\title{
The Structure of the Thallus of Neomeris dumetosa, Lamour.
}

\author{
BY \\ ARTHUR H. CHURCH, B.A., B.Sc., \\ Jesus College, Oxford. \\ With Plates XXI, XXII and XXIII.
}

$\mathrm{O}$

UR knowledge of the structure of the species belonging to the remarkable genus Neomeris is based on the account of the Madagascar species $N$. Kelleri given by Cramer ${ }^{1}$, who describes very fully the anatomy of the fullgrown plant and figures some of the earlier stages from spiritmaterial. Whether or not Solms-Laubach ${ }^{2}$ is correct in his statement that Cramer's $N$. Kelleri is identical with his own $N$. anmulata, Dickie, from Mauritius, it is generally agreed that $N$. dumetosa represents a distinct form; and this species has not yet been fully investigated owing to lack of suitable material. The older figures of Sonder ${ }^{3}$ and Agardh ${ }^{4}$ are very incomplete, as also are Cramer's, whose measurements are quoted in the specific description given in De Toni's Sylloge Algarum, No. 1065 .

${ }^{1}$ Ueber die verticillirten Siphoneen. Zürich, 1887. Ibid. Part II. Zürich, I890.

2 Ann. du Jard. Buitenzorg, Vol. xi.

${ }^{3}$ Die Algen des tropischen Australiens. Hamburg, $187 \mathrm{I}$.

4 Till Algernes Systematik. Lund, I887.

[Annals of Botany, Vo1. IX. No. XXXVI. December, 1895.] 


\section{Church.-The Structure of the Thallus of}

$N$. dumetosa, originally collected by Richard in the Antilles, and Harvey in the Friendly Islands, occurs also, according to Solms, in the island of Flores and New Guinea. I am indebted to Professor Vines for the opportunity of examining spirit-material of this species collected by Mr. H. N. Ridley at Singapore. The plants, Mr. Ridley informs me, grow in smooth shallow water, attached to mud or piles, and, when living, each individual looks 'very much like a little green sausage.' They reach a length of 3.5 to $4 \mathrm{~cm}$., and vary from 2 to $2.5 \mathrm{~mm}$. in diameter; the main axis is flexible and bears a delicately calcified upper portion, ill-adapted to withstand damage from rough water or pebbles, thus forming a striking contrast to $N$. Kelleri, Cramer, which is a densely calcified and stunted species growing, according to Keller, between coral-blocks exposed by the tides. It is possible, therefore, that $N$. dumetosa may prove a more typical species of the genus than N.Kelleri. Associated with the adult plants were younger specimens in all stages of growth, and in tracing the course of development evidence appears to be forthcoming to show that $N$. dumetosa, in consequence possibly of exposure to fairly constant and peaceable environment throughout its entire life, recapitulates in its ontogeny, not only its own phylogeny, but sufficient of that of the whole group of the Dasycladaceae to shed light on the relationships of the genera comprised in this remarkable order.

The history of development, in the specimens examined, falls naturally into five stages, of which the fifth constitutes the adult reproductive form.

\section{Stage $I$.}

The youngest plant in the material at my disposal (Fig. 1) consisted of an erect Vaucheria-like coenocytic filament, $5 \mathrm{~mm}$. in length, attached to the substratum by a typical dichotomously-lobed basal portion, and bearing at its apex a whorl of six dichotomously-branched filaments, delimited from the main axis by perforated septa. At points further down the axis two other nodes were marked out by the presence of 
circular scars representing the points of attachment of previous whorls of similar deciduous lateral appendages. In this specimen the lowest whorl of scars was $4 \mathrm{~mm}$. from the rhizoid portion; but six other specimens of the same length, though slightly older and showing 4-8 whorls of scars, agreed in the position of the first scars at a distance of about $2 \mathrm{~mm}$. from the base. The first whorls of filamentous appendages are formed at varying distances along the main axis; but as growth proceeds, development becomes more regular and the length attained by the internodes is fairly constant in the growing region. In the older portions, as the tubular axis increases in breadth, and the wall in thickness, the internodes are correspondingly shortened, and the zones of old scars rapidly become pulled down close to one another and finally obliterated. It is thus only in comparatively young plants, in this first stage of growth, that the first-formed whorls can be traced right down the axis, and in such cases there appeared to be a general agreement in the first whorl being formed at a distance of 1.5 to $2.5 \mathrm{~mm}$. from the basal portion; and though the comparative elongation of these young specimens at first suggested that they might be merely spindly etiolated specimens, owing their poor development to their being crowded out by the more mature individuals, their close agreement in the structure of the few lower millimetres and the known effects of later increase in diameter of the main axis may fully justify the acceptance of these as normal specimens; the later apparent slowness in longitudinal extension of the thallus as a whole being due to the counterbalancing shortening of the basal internodes (Fig. 20). The first stage, therefore, marks the direct assumption of the Dasycladus type of thallus, and this structure is maintained for many nodes. With increasing bulk of the axis, the number of appendages in a whorl increases (I2-I8), while the lateral appendages themselves reach a higher degree of complexity, ultimately consisting of 3-4 times di- or trichotomizing filaments, corresponding to the 'articulated ramelli' and 'byssoid fibrils' of Harvey which occur in allied genera. The constituent segments of these 


\section{Church.-The Structure of the Thallus of}

appendages are delimited by similar perforate septa, and detach, leaving circular attachment-scars similar to those found at the junction of the whole appendage with the main axis. On the upper nodes the perfect appendages form a tuft of assimilating filaments ('coma') about $2 \mathrm{~mm}$. in length; but further back the basal segments of the appendages alone persist, and these also ultimately disappearing, leave only their scars of attachment, which may be traced down the axis, becoming transversely elongated and more faintly defined on the lower portions, until they can be no longer accurately followed. On a well-grown specimen in this stage (Fig. 2), $18 \mathrm{~mm}$. in length, 79 zones were counted; this was the highest number observed in a plant wholly in Stage I; the upper 5 nodes being in full plumage, while basal segments of appendages remained to a greater or less extent on 23 nodes, and $5^{\mathrm{I}}$ whorls of scars could be traced back to a distance about $2 \mathrm{~mm}$. from the rhizoid portion. Twelve other plants, wholly in Stage I, varying in length from IC-I $8 \mathrm{~mm}$., possessed $27-79$ whorls of scars or else nodes with segments still attached. Thus an average specimen, I $3 \mathrm{~mm}$. long, would have attained to 40 whorls. Specimens passing on to Stage II in the apical region, as a rule, showed scanty traces of any basal segments of appendages belonging to Stage I attached to the lower part of the axis, and the number of whorls of the first type of appendage possibly varies considerably; thus, one plant, $15 \mathrm{~mm}$. long, passed on to Stage II at the $55^{\text {th node }}$ another, II $\mathrm{mm}$. long, at the 40 th, while a specimen figured (Fig. I0), with 23 apical whorls more or less in Stage II, showed over 80 whorls of scars to within $5 \mathrm{~mm}$. of the base. Again, reversion to Type I occurs very generally in the early development of Stage II (Fig. 10 b). Branching of the main axis occurs commonly in the basal portion below the first whorl of scars, abortive branches or outgrowths being found on half the young specimens examined. In some cases, such a branch led to definite development (Fig. 5) ; while indications of the possibility of a formation of new individuals from stolon-like outgrowths, 
which assist in the work of attachment, were also met with (Fig. 5 a). No creeping rhizome-filaments were observed, nor any formation of a special food-containing reservoir, as described in Acetabularia; but the storage of starch, in the form of large grains, throughout the whole of the rhizoid portion, was often very marked (Fig. 6). Once the thallus has assumed the whorled type of growth, branching of the main axis only occurs as an anomaly (Fig. 8); but in one specimen branching into two equal individuals occurred just above the first formation of the appendages of Stage II, and before it had become permanently fixed (Fig. 4). No case of branching was met with beyond Stage II, and this is perhaps important in reference to the branching of the main axis in Cympolia. Rejuvenescence of an axis on damage to the growing-point, and outgrowths due to wounds, may commonly occur; the contrast between the distant nodes of the young shoot and the shortened internodes of the old axis being especially well marked in such a case (Fig. 3).

\section{Stage II.}

As already indicated, the nodes now tend to be formed closer together, and the whorls of members become more regular in development. The characteristic feature of this stage is the delimitation of a basal portion from the basal segment of the appendage by means of a typical perforated septum formed as a ring-wall in the segment; the portion abstricted roughly equalling in length an internode of the main axis (Fig. Io a). This takes place with great regularity and symmetry in all the new whorls, and these abstricted portions, on disarticulation of the remainder of the appendage to which they belong, persist as more or less complete whorls of short segments ; every segment retaining at its distal end a single scar, and thus presenting a marked contrast to the long basal segments of Stage I, which exhibit at their extremities the two scars of the first dichotomy (Fig. 7). The 3-4-times dichotomizing appendage, which now appears to be borne at the end of this second type of basal segment, 
presents no peculiarity beyond a further increase in the length of its segments. Only the upper whorls of the plant possess undamaged appendages; those further back retain for a considerable period the short basal portions of Stage II, but present few traces if any of Stage I. The base of the main axis is now becoming considerably thickened by internal apposition of layers; wear and tear of the outermost layers which alone were perforated at the older scars, together with alterations in volume of the main tube, soon lead to obliteration of the first-formed scars, and in this and further stages, as a rule, no traces of earlier formations remain.

This second type of lateral appendage also obtains for many nodes; thus, 4 specimens averaging $16 \mathrm{~mm}$. in length, and showing traces of Type I attached to a lower whorl of scars, while the apex was passing on to Stage III, gave evidences of the second type of formation on 28-46 nodes ; the average being 37. Again, II specimens, IO-I9 $\mathrm{mm}$. in length, in which the apical whorls were passing on to Stage III, but in which no trace of Stage I remained, showed relics of basal segments of the second type on 28-84 nodes. Thus, an average plant, I $5.5 \mathrm{~mm}$. in length, would have laid down 50 whorls of appendages of the form characteristic of Stage II.

\section{Stage III.}

The short basal portions, formed, as shown, by abstriction from the elongated basal segments of Stage I, remain fairly constant for Stage II (Fig. II) ; but, in later-formed whorls, they exhibit a tendency to dilate, especially on the acroscopic surface (Fig. I2), and thus soon come into lateral contact with their neighbours. This dilatation may increase by degrees over several internodes, or may be so hastened that the transition is complete in passing from one whorl to the next; the ultimate result being the formation of a 'cortex' of bladder-like basal segments, completely hiding the main axis, and appearing externally as a facetted layer, of which the component units are pressed into close lateral contact, 
without any pronounced adhesion of cell-membranes (Figs. I 2, I4, I6). The contrast between the branched 'assimilating filament' and its expanded basal segment is now very marked, and the terminal portions henceforth assume the appearance of mere hair-like appendages; but it must be carefully noted that their morphological value will remain unaffected. When these terminal portions become detached, the axis remains clothed by a pseudo-parenchymatous onelayered cortex (Fig. I4), the constituent members of which differentiate into pedicelled vesicles, and exhibit a single scar as in Stage II (Figs. 14, 16). In the older parts of the axis, they again become isolated, and gradually fall away, leaving as in previous stages their whorled attachment-scars on the main axis (Fig. I3). Cases of reversion to Stage II frequently occur ; very generally, a dozen or more whorls of the second type may be intercalated after 12-20 whorls of Type III ; but reversion becomes rarer once the type has become long established.

A median longitudinal section of the apex at this period shows that the structure, attained by the plant after an average of 100 nodes, is recapitulated in about 5 nodes at the actual growing-point (Fig. I5); thus, delimitation of the basal portion, characteristic of Stage II, occurs in the third whorl behind the apex of the main axis; the dilatation of the lower segments results in lateral contact being complete at the fifth node; and in a few more internodes the form characteristic of Stage III is attained (Fig. I6).

As examples of the extent to which Stage III is retained in the life-history, the following may be taken : one specimen, possessing traces of Stage II on 25 whorls of scars, afterwards developed 98 whorls of Stage III; the apex still continuing the formation. This was the highest number observed. On the other hand, I I specimens, retaining traces of Stage II on the lower scars, while the apical whorls were in Stage IV, and whose length varied from I4-19 mm., showed 7-77 whorls of Type III. Thus, an average plant might have formed 43 whorls of Stage III and be passing on to the 
next stage and yet be only $\mathrm{I}_{5} \mathrm{~mm}$. in length, owing to the compensating contraction of the lower part of the main axis.

\section{Stage $I V$.}

A transition now takes place to a more elaborate type of cortex. The passage is sudden, and, as a rule, complete in all the members of a single whorl, though occasionally mixed whorls may be found (Fig. 22).

Instead of a basal portion of the lowest segment of the lateral appendage dilating to form a cortical facet, and bearing the rest of the segment and further ramifications as an assimilating filament, the whole basal segment forms a pedicel supporting the segments of the first dichotomy, and it is the lower portions of these segments of secondary order which now become swollen vesicles and repeat the cortex-formation (Figs. I7, I 8, 2I). The cortex has therefore, as it were, moved one degree outwards. The basal segments have again a characteristic appearance (Fig. I9), being short with two strongly pronounced distal scars, and as before they may persist on the main axis long after the loss of the cortical dilatations.

Reversion is general at first. For example, in a welldeveloped young plant (Fig. I7), Stage IV was initiated after formation of 42 whorls of Stage III ; but, after 4 whorls of the new type had been laid down, a reversion to Stage III occurred for 3 nodes; Stage IV being afterwards resumed and its whorls maintained in unbroken succession.

As the branching of the first dichotomy takes place in a horizontal plane, contrary to the method observed by Cramer in $N$. Kelleri, the new cortical whorls will exhibit twice the number of facets on the surface of the thallus in transverse section. If these are to be of equal size to those of Stage III, longer pedicels will be required, and the diameter of the thallus will thus be increased. Transitions from one stage to the other will therefore result in the production of a more or less moniliform appearance (Fig. I7); and this again is a foreshadowing of what becomes in Cympolia the 
normal structure. A section of the growing-point at this period (Fig. I 8) shows the origin of this new type of appendage to be due to a precocity of development of the first dichotomy of the member, accompanied by a laying down of septa above, instead of below, the first point of bifurcation; all earlier stages, therefore, cease to be recapitulated, the third node from the apex is already unmistakably Stage IV, and the growing-point henceforth lays down only appendages of this new and improved pattern. In the nearest approach to the actual transition obtainable in the neighbourhood of the apex (Fig. I 8), the junction of the secondary segments to form a continuous cortical layer was just completed in the 9 th node behind the apex. The number of members in a single whorl now reaches $16-22$, and this number steadily increases with increasing bulk of the plant.

Stage IV may be regarded as the adult sterile condition; its formation may be continued over $200-300$ nodes, the main axis slowly increasing in length to $25-30 \mathrm{~mm}$. Compensating contraction of the older internodes still proceeds, and, in an older plant of this stage, the two-scarred basal segments may be traced almost to the base of the plant. Before being entirely obliterated, the whorls of old scars become pulled down so close together that it often becomes difficult to isolate the scars of one particular node; at the same time, the individual scars become greatly elongated transversely to eye-like markings, while the cellulose plug which closes the septum retains its sharp contour to the last (Fig. 20). Reversion to a previous type of appendage on a large scale occasionally happens, but only in one case was a considerable interpolation of Stage II observed. Such phenomena may possibly be the result of injury to the growing-point, and in these cases the thallus will appear markedly constricted. Similar non-calcified constrictions have been described by Cramer in $N$. Kelleri, and these again present suggestions of the normal structure of Cympolia.

Calcification of the lateral appendages sets in after formation of a number of whorls of Stage IV, which may reach 
to 100-200, but varies considerably in different specimens. The apex does not calcify, the first trace of deposit being found at about the tenth node from the growing-point. The whole of the surfaces bounding the cavities beneath the cortical layer are incrusted, the maximum deposit forming a layer beneath the dilated ends of the cortical segments, perforated only by the pedicel portions. The deposit appears as an extremely fine precipitate of calcium carbonate in a mucilaginous outer layer of the cell-membrane (Fig. 2I), but further details may be left for consideration in connexion with the calcification of the mature thallus.

\section{Stage $V$.}

As already shown, the plant vegetates for a considerable period in Stage IV, increasing steadily in length, diameter of the main axis, and number of appendages in a single whorl (Figs. 28, 29); these last being $30-32$ in the mature plant. The new epoch is inaugurated by the appearance of the reproductive organs as new and special formations. These arise as outgrowths of the basal segments in the angle of the first dichotomy of the appendage, that is to say, in the angle between the cortical segments (Figs. 32, 33). Appearing first at the 6th node from the apex in the form of a papilla-like projection at the extreme distal end of the basal segments, they soon develop into spherical stalked structures, and are delimited from the rest of the lateral member by the characteristic ring-septum. They possess abundant protoplasmic contents and chlorophyll, and rapidly calcify. At about the 6oth node from the apex they are plugged off by a cellulose stopper (Fig. $3 \mathrm{I}$ ). The contents round off, and secrete a new cellulose membrane which fits closely the spherical terminal portion of the structure ${ }^{1}$ (Fig. 27). Although further development is unknown, there can be little doubt that we have here to deal with an aplanosporangium containing a single aplanospore. The formation

1 Cramer, loc. cit., p. $3^{1}$; Solms, loc. cit., p. 64 . 
of aplanosporangia is common to the whole of the Dasycladaceae with the exception of Dasycladus clavaeformis, in which Berthold ${ }^{1}$ has described the direct development of gametangia, and also Cympolia, which, according to Cramer, appears to follow Neomeris, but no specimens were observed in which the sporangia had developed sufficiently far to be plugged off from the segments bearing them, while the interesting observations of $\mathrm{Solms}^{2}$ on a case of apospory await further confirmation. The essential point to notice in Neomeris, however, is that we have here, side by side with a high degree of differentiation in the vegetative thallus, a presumably higher type of reproductive organ; since the aplanosporangia which in Acetabularia, for example, are morphologically equivalent to one segment, or possibly a whole appendage, and give rise to many aplanospores, here arise as special and later outgrowths on the appendages, and are restricted to the production of a single aplanospore ${ }^{3}$.

Only the upper portion of the adult plant possesses the full appendage of Stage V (Fig. 23) as a thrice di-trichotomizing member, of which the lower segments are highly differentiated, while the ultimate ramifications remain delicately filamentous. Further back the calcified cortical segments break away, leaving the incrusted basal segments, bearing the aplanosporangia, exposed to view; on the loss of these latter, the basal segments remain as three-scarred structures (Fig. 25), and may persist for a considerable period, though soon undergoing decalcification. Starch is generally distributed throughout the plant, the aplanosporangia being filled with large grains. Inulin also occurs in the form of small irregular

1 Bot. Zeit. p. 648 , I880.

${ }^{2}$ Loc. cit., p. 74 .

${ }^{3}$ In describing the reproductive organs of Neomeris, I have so far used the words 'aplanosporangium' and 'aplanospore' as being generally accepted terms. But while there is no need to fully discuss here the question of the alternation of generations occurring in the life-history of these forms, it must not be overlooked that, as Bower has pointed out (Annals of Botany, vol. iv, p. 356), all these plants are really sexual forms, i. e. gametophytes. No progress can be made toward a conception of the phylogeny of the group until it is clearly understood that the vegetative thallus of all the genera of the Dasycladaceae is directly homologous with that of Dasycladus itself and the other admittedly sexual Siphoneae (see p. 598). 
sphere-crystals, and is especially noticeable in the cortical segments of Stage IV. Calcification becomes more pronounced, and is remarkable for its limitation to definite areas (Fig. 24); but it never reaches the massive incrustation of $N$. Kelleri. The layer beneath the dilated ends of the cortical segments becomes much thickened and forms a continuous calcareous jacket, perforated by the slender noncalcified pedicel-portions of the cortical segments; a small deposit is laid down on the basal segments; the main axis, growing-point, surface of the thallus, and filamentous portions of the appendages do not incrust; but the aplanosporangia are densely coated to a distance more than half-way down their pedicels (Figs. 24, 30).

Relation of $N$. dumetosa to the rest of the Dasycladaceae.

From the observations above recorded on the youngest plants available, it may be reasonably concluded that $N$. dumetosa commences its life-cycle as an organism presenting the appearance of a Vaucheria; that is to say, a coenocytic filament without transverse septa, possessing a dichotomously-lobed rhizoid portion, and exhibiting a general tendency to form branches at right angles to the main axis and equal to it in diameter. This continues only for a length of two or three millimetres, when the whorled Dasycladus type is suddenly assumed. A similar filamentous stage has been shown by De Bary to occur in Acetabularia mediterranea; $N$. dumetosa, however, is more precocious in development than this Acetabularia, which reaches a length of over $20 \mathrm{~mm}$. before growing the first whorl of appendages, and thus agrees with the youngest stage observed in $N$. anmulata by Solms-Laubach.

After the definite assumption of the whorled type of growth, the study of the development of $N$. dumetosa resolves itself into a question of the variation in form, number, and composition of certain lateral appendages.

Reviewing the different stages of growth, I think it will be 
readily granted that the primary type of Dasycladean appendages is the polytomizing coenocytic filament, with constriction or incomplete septation at the points of origin and ramification. This again is morphologically of foliar nature, the whorled lateral appendages of Dasycladus itself being regarded by Nageli as definite leaves: specialization of the appendage as a distinct foliar member is indicated, not so much by its limited growth, as by its being endowed with a certain partial individuality which ultimately finds anatomical expression in the formation of perforated septa. Such septa never occur at the points of ramification of the main axis, and in the 'leaves' they are correlated with a deciduous habit. That the leaf repeats in its own ramification the same whorled type which obtains in the main axis, though in an abbreviated form, does invalidate its foliar nature; the essential point to notice being that here also the secondary segments arise as simultaneous whorls.

The archetype of the Dasycladaceae may therefore be conceived to have consisted of a main axis bearing whorls of several times polytomizing foliar appendages; and these, after functioning as assimilating leaves, possibly became wholly converted into gametangia, after the manner of such a recent type as Bryopsis. The nearest approach to such a form of reproduction, within the limits of the Dasycladaceae, occurs in Dasycladus clavaeformis, in which, according to Berthold, the whole protoplasmic contents, when the reproductive stage is attained, stream into the specially formed gametangia. The first stage in the development of $N$. dumetosa may be regarded therefore as a recapitulation of the primitive 'Proto-Dasycladus' type of thallus. The same stage occurs in the life-history of Acetabularia, in which plant the polytomizing filament may be seen at its best development, and in Polyphysa (Agardh, Cramer, Solms) and Halicoryne (Cramer, Solms); while it persists as the adult condition in Botryophora occidentalis Agardh, Chlorocladus australasicus Sonder, and Eudasycladus clavaeformis. Of these last, Botryophora approaches most nearly the earlier condition of the type in its 


\section{Church.-The Structure of the Thallus of}

elongated internodes and long wavy segments; Chlorocladus with a terminal 'coma' recalls the later type of Stage I (Fig. 2); but on the other hand, while retaining a primitive type of thallus, all three of these genera have specialized their reproductive organs, and these arise as new outgrowths from the leaf, borne either laterally or in the angle of its ramification. In the latter case, owing to their contents being delimited by septa similar to those as the points of ramification of the leaf, they have often been described as leaf-segments. Dasycladus clavaeformis alone retains a definite gametanguim, the others attain to the so-called aplanosporangia.

Exceptional cases of branching of the main axis to form two equal individuals, previously noted for Stages I and II of $N$. dumetosa, find a parallel in similar examples in Acetabularia mediterranea ${ }^{1}$, Botryophora occidentalis ${ }^{2}$, and they may also be observed in Dasycladus clavaeformis.

The meaning of the delimitation of a special basal segment in Stage II, is at first sight not clear; it can scarcely be a mechanical necessity, nor can it be regarded as purely transitional to the cortex-formation of Stage III. The fact that the type is retained in a high state of perfection for as high an average number of whorls as is the case in Stage I or Stage III, may be taken perhaps as an indication of its importance at some period in the life-history of the group. Perhaps a reasonable working hypothesis is that we have here the first step in the specialization of the 'leaf' into assimilating and reproductive portions, and that the basal portion represents the primary gametangium for the Dasycladaceae, with the exception of the three previously noticed Dasycladus types which have specialized their reproductive organs as new outgrowths on a thallus which is structurally in Stage I. There is no difficulty in conceiving such a Dasycladus type in which the protoplasm of the leaves, on reaching the reproductive stage, streamed down to the lower portion of the basal segments and there cut itself off by a septum; after

1 Woronin, Ann. Sci. Nat. I862.

2 Cramer, I. loc. cit., Taf. V, 2 I. 
the fall of the filamentous portion, the whorl of gametangia would then persist on the main axis much as in the older stages of Stage II. This second type of leaf occurs again in the adult plant of Cympolia barbata, where according to Cramer ${ }^{1}$, the non-calcified whorls of the nodal portions of the axis are of this type, and, when first formed, bear the full filamentous terminal portion.

Again, the remarkably symmetrical habit of one of these whorls of short members suggests nothing so strongly, at first sight, as the cap of Acetabularia. The publication of SolmsLaubach's important monograph of the Acetabularieae ${ }^{2}$, just as the present paper is being completed, enables me to compare the hypothesis now put forward with the results obtained for these highly aberrant types of Dasycladaceae. Solms-Laubach concludes, from a careful comparison of species of Polyphysa and Acetabularia, that the ray-segments of Acetabularia mediterranea are to be regarded as, not so much a whorl of lateral appendages, as a development of lateral sporangia on the sides of appendages which have become extremely reduced and distorted, and he presents a series of types in support of his opinion; but the older view of the morphological value of the cap of $A$. mediterranea seems so simple in comparison with the new one, that until the former has been definitely proved to be impossible, it will doubtless retain adherents. Again, Solms points out the difference between the Acetabulum section comprising $A$. mediterranea alone, and the Acetabuloides section, and here perhaps the possibility is not excluded, that, granting that the cap-type of thallus represents a form which has proved itself a success in relation to special environment, a cap may have been evolved at different points in the phylogeny of the group, and that these may resemble each other by convergence of type. Thus, according to the older view, the formation of a cap-whorl in $A$. mediterranea seems to be accompanied by a telescoping of the main axis in the neigh-

1 I. loc. cit., Taf. IV, Fig. 4.

2 Trans. Linn. Soc., Vol. v, I. 


\section{Church.-The Structure of the Thallus of}

bourhood of the cap, and the superior and inferior coronae may be regarded as belonging to the main axis rather than to the cap-rays. The marked radial arrangement of the scars on the corona superior of $A$. mediterranea seem to point definitely to such a correlation, and we have in addition the general habit and external form which in a coenocytic plant may be considered of some importance. Solms-Laubach bases his view on the presence of a certain septum formed within the apparent attachment of the coronae to the caprays; it may, on the other hand, be objected that it has not been shown that this septum is of primary morphological significance, and that it necessarily implies the point of origin of an appendage. Whether $A$. mediterranea may be regarded as representing a survival of a highly specialized and aberrant form of Stage I or Stage II, or not, thus correlating the caprays with the basal portions of appendages or whole appendages reduced to a single segment, it is only important to point out here that Acetabularia must have diverged from the Proto-Dasycladus type at some point, and that in searching for this point the capacities for variation of the normal Dasycladean appendage must first be exhausted.

Again, the fact that the swollen cortical segments of Stage III can neither subserve protection nor support, since they neither enclose the apex, nor persist on the lower portions of the axis, suggests that this stage marks a tendency to compact aggregation of the reproductive organs which are being developed from the specialized basal segments which now increase in bulk, bulge out especially on their basiscopic side, and thus tend to expose the maximum surface in a plane at right angles to the incident light (Fig. I6). A similar type of appendage occurs, according to Solms-Laubach ${ }^{1}$, in the life-history of Cympolia van Bossei; while it is also probable that the fertile appendages of Halicoryne Wrightii may be placed here. The legume-like aplanosporangia of this species were described by Agardh rather incompletely, but such

1 Annales Jard. Buitenzorg, xi, Plate VIII. 
a correlation would be further supported by the discovery by Solms ${ }^{1}$ and Cramer ${ }^{2}$ that these each possess in the young condition 'solitary dichotomously branched hairs' placed laterally. The peculiar aberrant form may be regarded as a further development of the tendency to bulge on the basiscopic side. The most remarkable feature, however, in Halicoryne Wrightii is the late formation in the fertile segments of a new septum delimiting the reproductive 'pod' from a pedicel-portion. This small detail, described by Agardh and confirmed by Solms-Laubach ${ }^{3}$, is the first definite indication of a point of extreme importance. We have here the late formation of a secondary septum for the obvious physiological purpose of delimiting the reproductive coenocytic mass of protoplasm; that is to say, the Dasycladaceae may form septa of two kinds : first, those which occur in connexion with the assimilatory processes; secondly, those formed in correlation with the necessity for the isolation of the developing gametes. The septa of the first order indicate a high degree of specialization of the leaf as an assimilatory organ; the septum, by preventing extensive streaming movements of the protoplasm, under the stimulation of external agencies, provides for an even distribution of protoplasm and chlorophyll-corpuscles in the assimilating segments; at the same time allowing free conduction and transfer of substances in solution in the cell-sap by the open pore. When the protoplasm of the segment has reached the end of its assimilatory activity, the pore is closed and that segment falls off. In the same way, the delimitation of the gametangium by a septum isolates the contained protoplasm, but allows free entrance by the pore to reserve carbohydrates, \&c. ; when the supply is complete, the pore is plugged by a cellulose stopper. But it must be noted, that while septa of the first kind, by being fortunately placed at the points of ramification of the leaves, afford valuable landmarks in determining the comparative morphology of segments, the

1 Monograph, Plate IV, Fig. 5.

2 Ibid. p. 39.

${ }^{3}$ Monograph, p. 30. 


\section{Church.-The Structure of the Thallus of}

septa of the second order, owing to the fact that the gametangia are not constant in position, do not necessarily possess an equal significance; that is to say, a septum does not necessarily imply a point of ramification or even origin of a leaf when reproductive processes are concerned. This again not only explains how it is that the special 'sporangial' outgrowths of Neomeris, for example, have been described as 'terminal branches,' and lends support to the hypothesis put forward in explanation of Stage II, as also further suggesting that the septum used as a landmark by SolmsLaubach in $A$. mediterranea may be a special formation in connexion with the high degree of specialization of the cap as a reproductive organ; but it leads on to the solution of the difficulty which seems to exist as to the real nature of the so-called 'aplanospores.' In these plants, it must be clearly understood, we are dealing not with cells, but with coenocytic masses of protoplasm. The special coenocytic masses which are entering on a reproductive phase, delimit themselves from the rest of the plant by a formation of membrane giving rise to a special gametangium, utilizing for the purpose at least some part of the original membrane of the vegetative thallus. This coenocytic mass in the majority of the recent genera undergoes further partition ; but the smaller coenocytic aggregates, instead of utilizing part of the membrane of the gametangium for their own investment, as in the segmentation of cellular tissue, form complete new membranes individually, and thus effectually isolate themselves. The so-called 'aplanosporangium' therefore is to be regarded, not as a spore-producing organ, but as a multilocular gametangium, of which the 'aplanospores' are the component loculi lying free inside the original membrane. The formation of solitary 'aplanospores,' as in $N$. dumetosa, represents, then, the retention of the latter mode of formation, only a single loculus being however developed, and points to a descent from a type in which numerous distinct loculi ('aplanospores') were developed. In the single 'aplanospore' therefore we have the highest type of gametangium attained in the Dasy- 
cladaceae. That such a mode of formation of a multilocular gametangium is of biological significance, in allowing for the dispersal of these isolated gametangia in the resting condition, is quite conceivable, and the interpolation of this phase in the life-history must be regarded as a phenomenon of adaptation to environment, and in no way interfering with the sexual character of the parent plant. The peculiar phenomenon already mentioned as having been observed by Solms in the germination of Cympolia gametangia must hence be included under the head, not of apospory, but of apogamy.

Returning to the consideration of $N$. dumetosa, it has already been observed that the transition from Stage III to Stage IV is startlingly sudden, and henceforth there is no apical recapitulation of previous stages. It is also to be noted that the cortical segments are again, not the second leaf-segments, but basal portions of these segments, as if the plan of structure which was worked out in the first segments had now been transferred bodily to the next further out. Possibly there is a gap in the record at this point; at any rate, the immediate result of the arrangement, on the foregoing view of the nature of the reproductive organs, would be a doubling of the reproductive segments. Such a type in which the basiscopic cortical segment becomes reproductive, while the acroscopic remains sterile, thus combining in a single whorl the alternation characteristic of Halicoryne, is suggested even more strongly by Solms-Laubach's figure of Polyphysa peniculus ${ }^{1}$, than the older drawings of Agardh and Cramer; the sterile segment bearing a true whorl of three filaments. If Solms-Laubach's view is correct, the Acetabuloides section may possibly be connected to the main series at this point, and may lead on ultimately to the Acetabulum type. I am however content to leave the discussion of the phylogeny of these types in the more competent hands of Graf zu Solms-Laubach, merely pointing out, as already indicated, the care required in dealing with septa as morphological landmarks. Thus, the septa which Solms-Laubach describes as cutting off the vestibules of 
Acetabularia cremulata are undoubtedly secondary, and this leads to the suggestion that the other septum below the coronae may possibly represent the formation of a special septum for the purpose of smoothly detaching the reproductive rays, at some earlier stage in the phylogeny.

The fifth type of leaf closes the series; other genera at this point, owing possibly to the greater capacity for protection in the cavities of the thallus, follow the plan of the simpler genera of the Dasycladus group, and originate the gametangium as a new outgrowth, either laterally as in Bornetella, or in the angle of ramification of the first dichotomy (Neomeris) or polytomy (Cympolia). This again may be regarded as a transition to a 'paraphysial type,' in which protection is afforded to the reproductive organs while in the early stages of development. At any rate, this is probably the function of the cortical layer in Neomeris; thus the gametangia are developed later, and when they are ready for dispersal, the calcified layer, either from contraction of the older internodes, or decalcification of its now non-assimilating members, becomes worn away and exposes them freely.

Finally, $N$. dumetosa suggests the lines along which differentiation has taken place in N. Kelleri and Cympolia. The calcification en masse of the latter is due, as Solms points out, to the fusion of the mucilaginous layers in the internal cavities of the thallus; while similar calcification of groups of adjacent gametangia in $N$. Kelleri into block-masses, so excludes light from the basal segments that they soon cease accumulating calcium carbonate. The tendency of $N$.dumetosa to reversion to a lower order of leaf is carried still further in Cympolia: cases in which $N$. dumetosa tended to revert after a dozen whorls or so have already been described; C. barbata, according to Cramer, reverts after $4^{-1} 6$ whorls of Stage V right back to $5^{-10}$ whorls of Stage II. Such extensive reversion was observed in one specimen only of $N$. dumetosa; the reversion and dichotomous branching at this stage, noticed as exceptions in the case of $N$. dumetosa, thus becoming the normal condition in Cympolia barbata. 
Whether the preceding hypotheses as to the evolution of the leaf and gametangium of the Dasycladaceae will hold or not, I think it remains sufficiently clear that the subdivision of the Dasycladaceae into the two sub-tribes Acetabularieae and Dasycladeae, originally proposed by Hauck and followed by Cramer and Wille, may prove too artificial. Agardh alone has insisted on the morphological identity of the Dasycladean appendage, though his conception was that the most reduced leaf was the highest type, and thus he headed the series with Acetabularia. At any rate, as I have already pointed out, this is the line which primarily demands exploration, the old distinction between 'fertile leaf' and 'sterile hair' resting on on satisfactory basis.

The phylogeny of the group as thus indicated may be expressed in such a form as the following :-

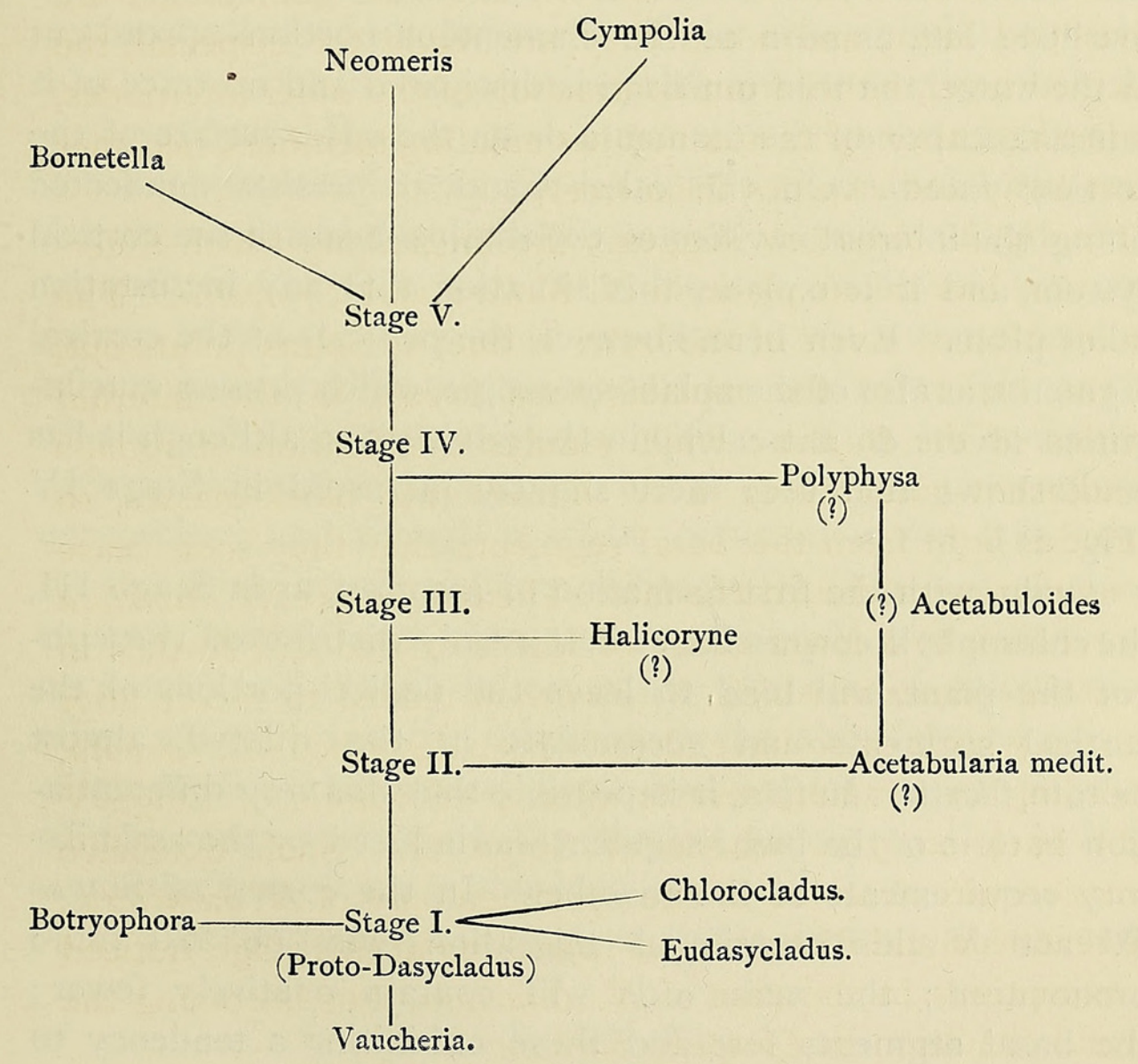




\section{Note on the Calcification of $N$. dumetosa.}

A comparison of sections of the calcified and decalcified thallus leads to the conclusion that the deposit of calcium carbonate is closely connected with two phenomena: the presence or absence of, first, an external mucilaginous layer on the cellulose membrane, secondly of chlorophyll-corpuscles (Fig. 26); and, in fact, that it is abundant on segments where both occur, but absent if either is for some reason wanting.

The growing apex of the main axis is covered by striated layers of clear hyaline mucilage, and the thick mucilaginous sheaths of the developing appendages of the upper half-dozen whorls form a series of striated layers filling the cavity of what may be termed the apical bud. This apical bud is formed by the inarching of about 16 whorls of appendages, and on the whole surface of these the mucilaginous layer is well marked; but, as soon as the filamentous portions spread out in the water, the thin mucilage is dissipated and no trace of it remains, either on the filaments or on the outer surface of the cortical facets. On the other hand, it persists unaffected lining the internal cavities of the thallus, beneath the cortical system, and it is only in this situation that any incrustation takes place. Even here, however, the pedicels of the cortical segments, as also of the aplanosporangia, which possess mucilaginous layers, do not calcify in the adult plant, although it has been shown that they were slightly incrusted in Stage IV (Fig. 2I).

Again, with the first formation of a cortex, as in Stage III, the chlorophyll-corpuscles, at first evenly distributed throughout the plant, will tend to leave the pedicel-portions of the cortical segments and accumulate in the dilated, almost peltate, facets. In fact, it is possible that this very differentiation in form of the basal segment was induced by the assimilatory requirements of the member. In the cortex of Stages IV and $\mathrm{V}$ this centrifugal migration will be still more pronounced; the main axis will contain relatively fewer; the basal segments few, and these exhibiting a tendency to 
collect at the distal ends of the segments, and the elongated pedicels of the cortical segments as also those of the aplanosporangia will be practically devoid of corpuscles; while, on the other hand, the dilated cortical facets and the spherical aplanosporangia will appear furnished with a dense layer (Fig. 26).

Nor will streaming movements of the protoplasm, entraining the corpuscles, bring about any great change in their distribution. The perforated septum being concave towards the cavity of each segment, revolution will take place around rather than through the pore; hence, although the corpuscles may accumulate at the distal ends of the basal segments (Fig. 26), few will pass on into the pedicels of the cortical segments ; and for the same reason, the narrower the pedicels become, and the more spherical the cortical facets and aplanosporangia, the fewer corpuscles will pass inwards. Exact demonstration of the behaviour of the chlorophyll-corpuscles is of course out of the question with spirit-material; but the observations of De Bary and Strasburger ${ }^{1}$ on the aggregation of the chloroplasts in young non-calcified plants of Acetabularia, due to their extreme sensitiveness to direct sunlight, lend support to the view that extensive movements of the corpuscles may take place in the cortical facets, without leading to any considerable migration into the pedicels. Hence the absence of incrustation on the pedicels is to be correlated with a diminution in the number of contained chlorophyllcorpuscles; and though a slight incrustation was laid down on the short broad pedicels of Stage IV (Fig. 2I), as these become narrow and elongated in Stage $\mathrm{V}$, the absence of corpuscles will result in an entire absence of calcification (Figs. 26, 30). On the other hand, the abundant supply of chlorophyll in the cortical facets does not lead to calcification of the outer surface of the thallus, owing to the lack of a mucilaginous layer in this locality.

The mechanism of calcification, so far then, admits of ready 
explanation: in direct relation to the energy of the assimilatory processes going on in the chlorophyll-corpuscles, a precipitation of calcium carbonate is formed in the surrounding medium; that part of it which deposits in the mucilaginous sheath will be 'fixed,' the rest will be washed away; further deposition takes place uniformly throughout the mucilaginous layer, and calcification becomes more and more intensified in direct proportion to the activity of the chlorophyll-corpuscles in the immediate vicinity. A suggestion that the maximum precipitation is not utilized in Neomeris dumetosa owing to scanty development of the mucilaginous layers, is afforded by the observation that calcification extends down the pedicels of the aplanosporangia to about a distance equal to nearly twice the thickness of the deposit over the spherical portion (Fig. 30, 3I); and this, again, agrees with the phenomena described by Cramer ${ }^{1}$ for Cympolia, the young parts of which are endowed with a copious mucilage. That the apex and upper twenty whorls or so show scarcely any trace of deposit in their mucilaginous sheaths may be due to the rate of growth being greater than the rate of deposition; but, more probably, it is to be explained by the assimilatory processes being less energetic in the growing whorls than the respiratory, so that, even were a deposit formed, the parts would tend to decalcify owing to excess of carbonic acid in the neighbourhood. It is not so easy, however, to suggest why calcification should not set in until Stage IV is well advanced. Precipitation will vary with the amount of calcium in the water, the intensity of the light, and the assimilatory activity of the chlorophyll-corpuscles in the segments; but, as the plants are colonial, and the clumps contain specimens in all stages of growth, the first two factors will be fairly constant, and it can only be concluded that it is at this stage that the intensity of chlorophyll-assimilation first becomes sufficient to destroy the equilibrium of the solution of calcium bicarbonate. It is interesting to compare De Bary and Strasburger's observations 
on Acetabularia mediterranea; here the young plant commenced calcification before it became attached to the substratum, and they suggest that a highly calcareous substratum is requisite for normal development. In view of the far greater deposit of lime in this species, it is evident that this must be the case, unless the energy of assimilation is correspondingly enormously increased.

Finally, with regard to the mechanism of precipitation, it cannot be claimed that the case of Neomeris presents a solution of the problem. Pringsheim ${ }^{1}$ has shown that a localization of calcification in species of Nitella is to be explained by local variations in the intensity of chlorophyll-assimilation; and he regarded all phenomena of incrustation as being due solely to abstraction of carbonic acid from the surrounding medium containing calcium bicarbonate in solution, and consequent precipitation of carbonate on the surface of the plant. That water-plants can live healthily in such a solution, and can obtain carbonic acid for assimilation by decomposing the bicarbonate, and that the carbonate is precipitated on their surface, has been conclusively shown by Hassack ${ }^{2}$; but only in a few cases did he succeed in obtaining a permanent incrustation, and hence falls back on the suggestion that there must be some peculiarity in the membrane of plants which normally calcify. Hassack, however, endeavours to show for Chara foetida, that the deposition may be referred to a precipitation of calcium carbonate outside the plant in consequence of the excretion of an alkaline carbonate, formed as a waste product in the assimilatory processes; and Schimper ${ }^{3}$ points out that such precipitation would present an analogy to the neutralization of acid potassium oxalate in the formation of secondary calcium oxalate.

The chief difficulty with regard to such an hypothesis for all calcification is, as Pringsheim suggested, the explanation of the extremely localized deposit. It is not easy to see why an alkaline carbonate should be excreted in the immediate

\footnotetext{
${ }^{1}$ Jahrbuicher, vol. xix, p. I $3^{8} . \quad{ }^{2}$ Untersuchungen, Tübingen, III, p. $4^{6} 5$.
} 


\section{Church.-The Structure of the Thallus of}

vicinity of the chlorophyll-corpuscles, as soon as formed, rather than tend to accumulate first in the cell-sap. Nor is the analogy with the case of secondary oxalate formation a strict one, since in this case the injurious acid oxalate is neutralized inside the cell, and the harmless calcium salt excreted. Further, Loew ${ }^{1}$ suggests that the observations of Klebs and Hassack on the formation of alkaline carbonate may be vitiated by peculiar reactions of the colour-test employed. It is evident that, in Neomeris, the precipitation takes place outside the membrane, and either hypothesis might account for its formation, but it may be pointed out that, even if precipitation be entirely ascribed to the excretion of an alkaline carbonate which still remains hypothetical, the withdrawal of carbonic acid from the surrounding medium will still play an important part in maintaining the incrustation. For, living in shallow water, it is evident that the free carbonic acid present in the medium, which tends to decalcify the calcareous substratum, would also tend to decalcify the incrusted plant; and it has already been shown that the older segments decalcify as their assimilatory activity ceases, and before they become finally detached from the main axis.

${ }^{1}$ Flora, I893, p. 4I9.

\section{EXPLANATION OF FIGURES IN PLATES XXI, XXII, AND XXIII.}

Illustrating Mr. Church's paper on Neomeris.

PLATE XXI.

Fig. 9. Natural size.

Figs. 7 and $I_{5}$ Zeiss 3 D., all the others Zeiss 3 A. Figs. I-8 reduced $\frac{1}{2}$. Figs. IO-I 6 reduced $\frac{2}{3}$.

Fig. I. Young plant of Neomeris dumetosa, bearing apical whorl of 6 members, and 2 whorls of 6 scars each,-enlarged view of apex at the side.

Fig. 2. Well-grown specimen in Stage I. Upper 5 whorls with full appendages. 
Fig. 3. Rejuvenescence of an old injured axis. The young shoot commencing with greatly elongated internodes.

Fig. 4. Exceptional case of dichotomy of main axis, just above first signs of Stage II.

Fig. 5. Basal portion of plant in Stage I. Branching of the main axis below the lowest whorl of scars. (a) possibly young branch developing from a creeping rooting portion.

Fig. 6. Root-portion of healthy plant. Starch-storage general in the lobes.

Fig. 7. Basal segment of Stage I, showing 2 apical scars.

Fig. 8. Anomalous branching of main axis in Stage I.

Fig. 9. Young plants (Stage I), natural size.

Fig. Io. Commencement of Stage II. (a) formation of the septum, delimiting the basal portion ; $(b)$ reversion to Stage I.

Fig. II. Young plant in Stage II, the upper ro whorls. In the water the lateral members stand out horizontally, they are shown closed in a pencil to give the symmetrical effect.

Fig. I 2. Transition to Stage III.

Fig. I3. Segments of the primary cortex, wearing off on older part of thallus.

Fig. I4. The primary cortex of Stage III after loss of the filamentous portion of the appendages.

Fig. I5. Apex of a young plant in Stage III. Cleared in Eau de Javelle to restore normal turgidity. Formation of cortex at fourth and fifth node behind the apex.

Fig. I6. Longitudinal section of Stage III, cortical segments enclosing a cavity.

\section{PLATE XXII.}

Figs. I7, 21, 22, 24, 25, 26, Zeiss 3 A. and reduced $\frac{2}{3}$.

Figs. 18, 19, 20, 27, Zeiss 3 D. and reduced $\frac{2}{3}$.

Figs. 28, 29, $\times 5$.

Fig. I7. Upper portion of plant passing into Stage IV after formation of $4^{2}$ whorls of Stage III. Reversion after 4 whorls and back again after 3 .

Fig. I8. Section of apex showing transition, after $3^{6}$ whorls of Stage III. Cortical layer in continuity at the ninth node from the apex. Stage IV laid down at the third node from the apex.

Fig. I9. Characteristic basal segment of Stage IV, showing 2 apical scars.

Fig. 20. Portion of main axis near the base. Transverse elongation of scars, the cellulose plug retains its circular contour. Number of members in a whorl at this point, I $4-16$.

Fig. 2I. Transverse section of plant in Stage IV, partly decalcified. The depth of shading indicates the amount of deposit, as seen by transmitted light. Number of members in a whorl, I8-20.

Fig. 22. Older portion of thallus at transition from Stage III to IV, showing irregularities in formation, and scanty remains of whorls of members.

Fig. 23. Full type of 'leaf' in Neomeris dumetosa, showing specialization of basal portion and addition of new outgrowth, the aplanosporangium, at the first bifurcation.

Fig. 24. Transverse section of adult plant at about the middle of its calcified 


\section{Church.-Neomeris dumetosa, Lamour.}

portion; partly cleared. The dichotomy in a transverse plane is less regular than in Stage IV. Half the members in a whorl undergo displacement at the surface, rendering the facetting less symmetrical. Number of members in a whorl, 30-32. Depth of shading indicates amount of calcification.

Fig. 25. Older portion of thallus after disintegration of cortex. The calcified aplanosporangia and calcified basal segments only left. These latter decalcify and persist some time. Many of the aplanosporangia also decalcify and exhibit no contents, but no rupture in the wall ; possibly sterile.

Fig. 26. Portion of transverse section, cleared and stained with Hoffmann's blue to show chlorophyll-corpuscles. Diagonal shading indicates the region of calcification in the mucilaginous sheath.

Fig. 27. Mature aplanosporangium enclosing a single spore, (?) gametangium. This latter invested with a thick cell-wall distinct from the thin membrane of the aplanosporangium. Contracted contents allow the wall to be clearly defined.

Fig. 28. Young plant in Stage IV, just commencing calcification. $22 \mathrm{~mm}$.

Fig. 29. Adult plant in reproductive stage. Spirit specimen showing region of cortical calcification and apical coma of filamentous appendages. Below, the disintegrating cortex exposing the densely calcified aplanosporangia. Further back the scanty remains of basal segments. $35 \mathrm{~mm}$.

\section{PLATE XXIII.}

The whole Zeiss 3 D. and reduced $\frac{2}{3}$.

Fig. 30. Basal segment of leaf bearing aplanosporangium. Calcified.

Fig. 3I. The same decalcified, showing mucilaginous outer layer of wall and contents of aplanosporangium rounding off to form a spore. Also delimitation by $\mathrm{T}$-shaped cellulose plug, not found in other septa.

Fig. 32. Median longitudinal section of apical bud of adult plant. Continuous cortex formed at node 9. At node 14 the cortical segments begin to assume globular extremities. First dichotomy in transverse plane, irregularities in facetting by displacement arise later.

Fig. 33. The same series of appendages in tangential view; bifurcation of Stage IV in 2. First sign of gametangium, as also delimitation of the cortical segments in 6 . The full filamentous portions not shown. Cleared in $\mathrm{HCl}$ and Eau de Javelle. 


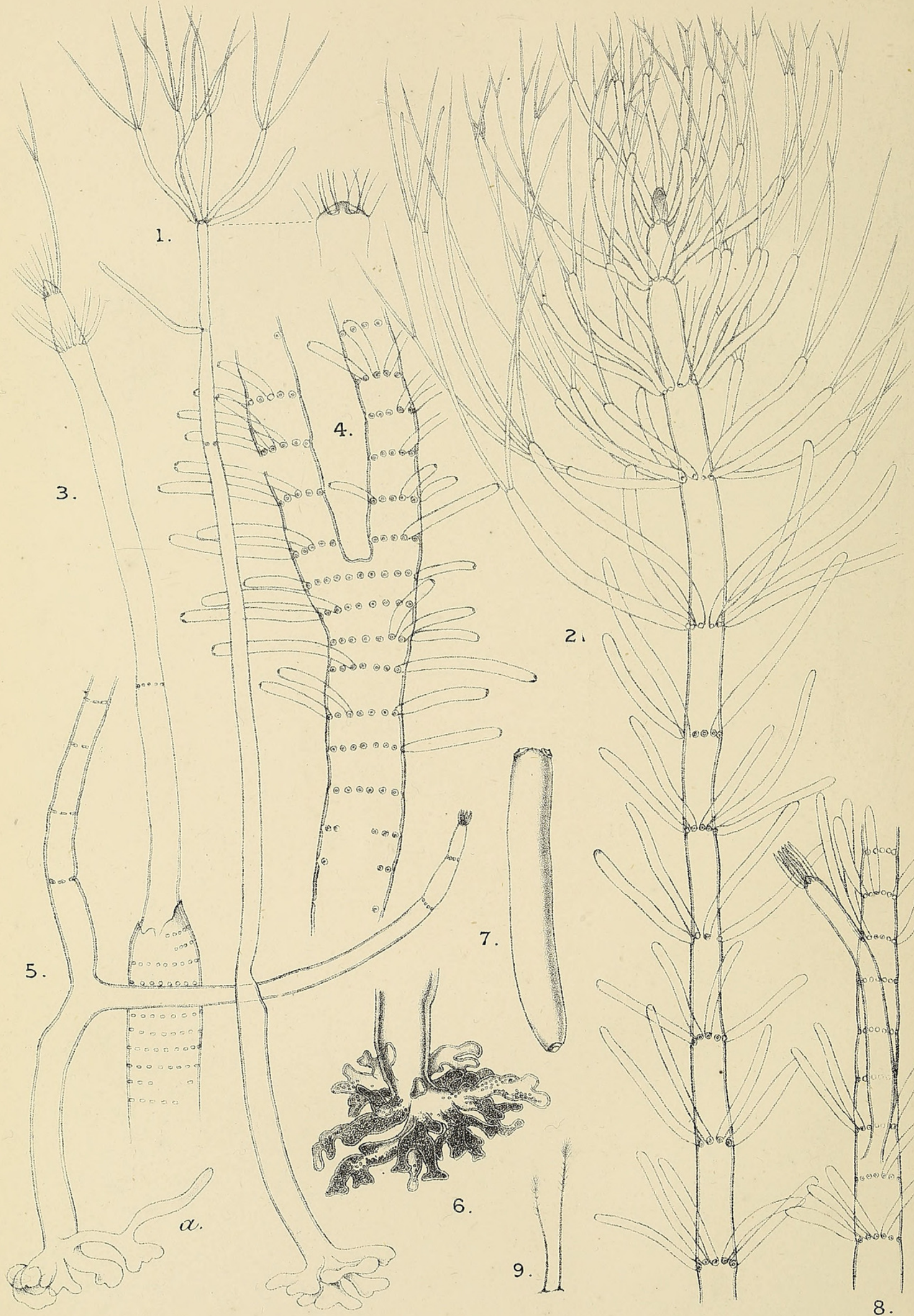

A.H.Church del. 


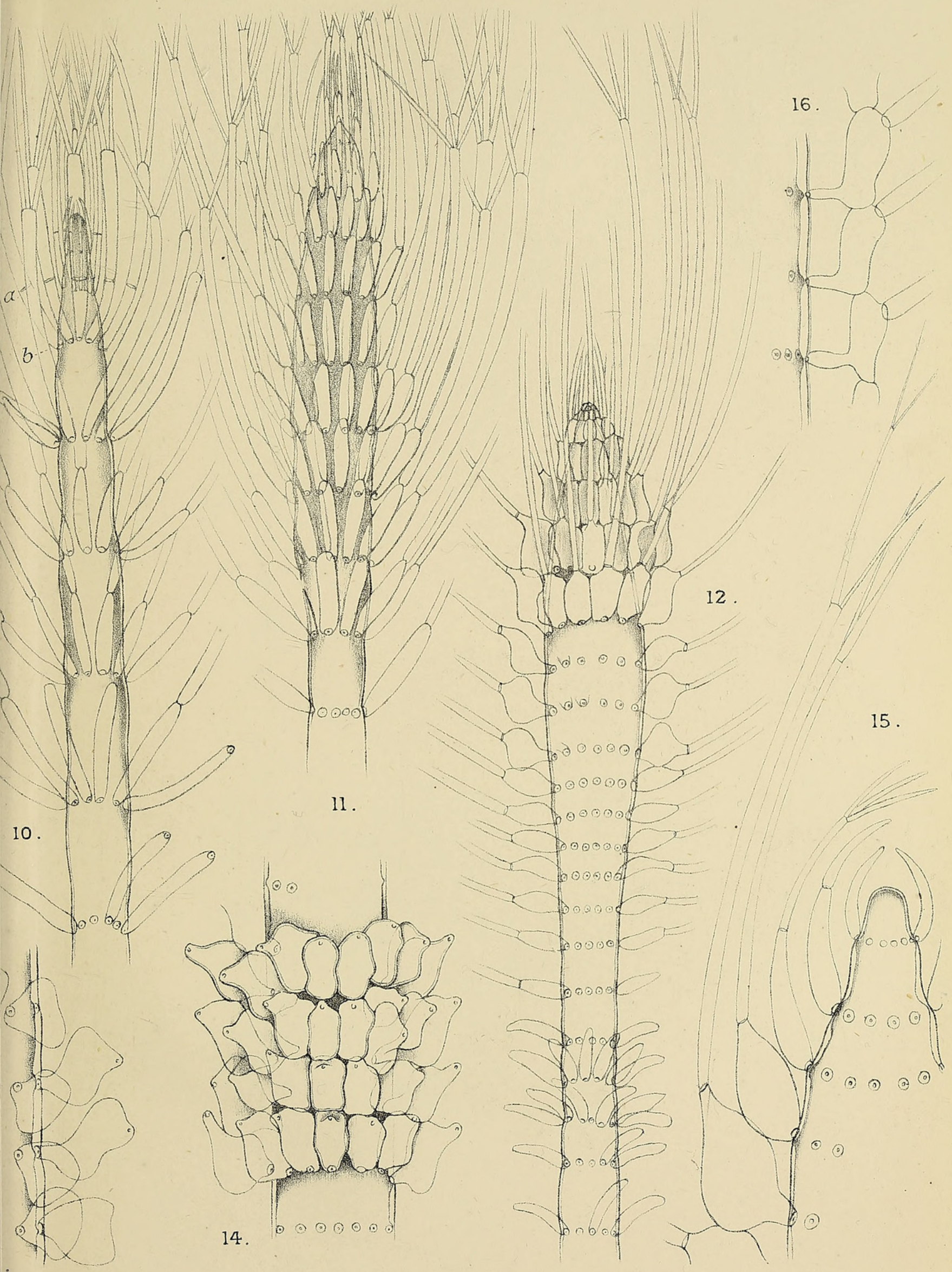

University Press, Oxford. 

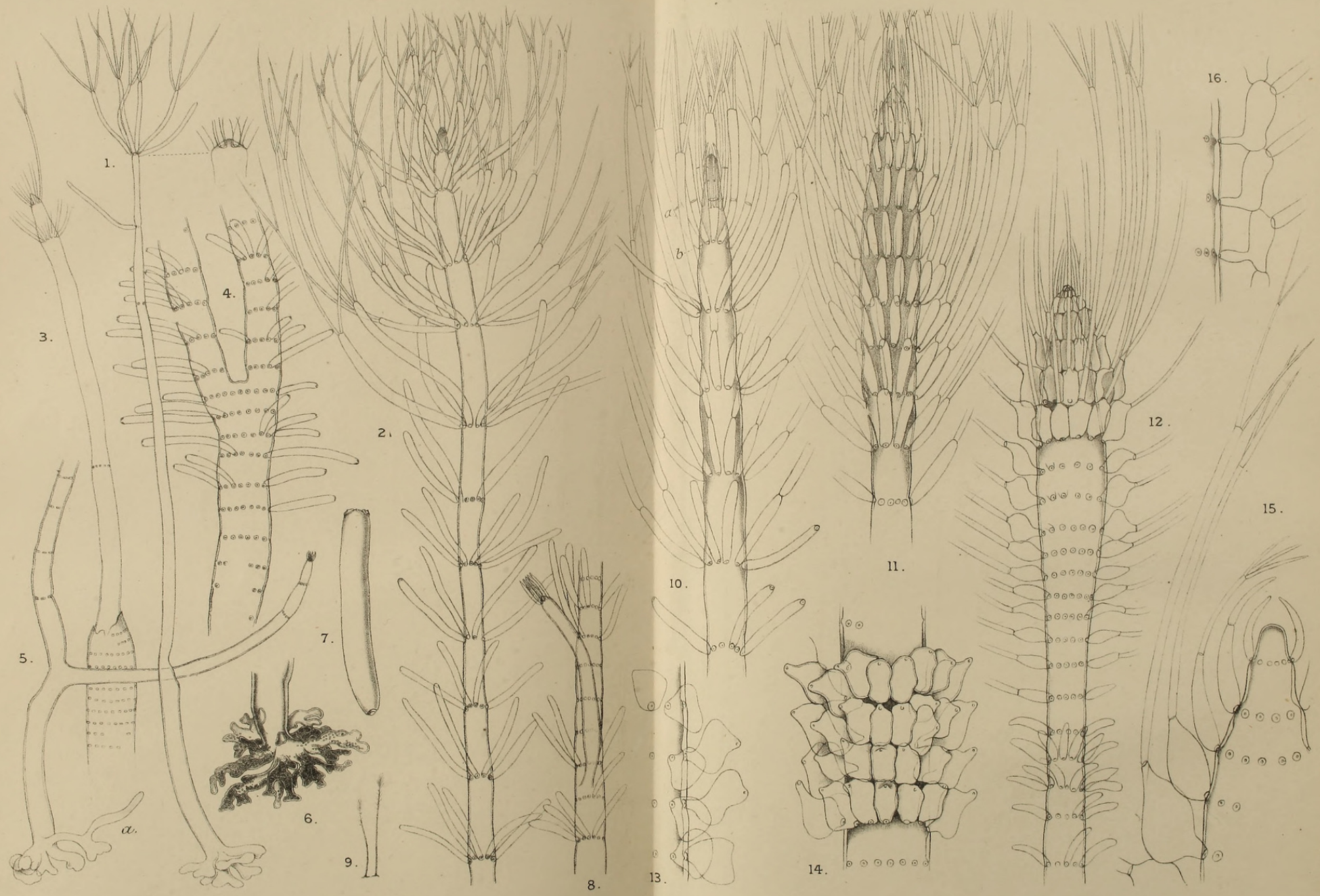


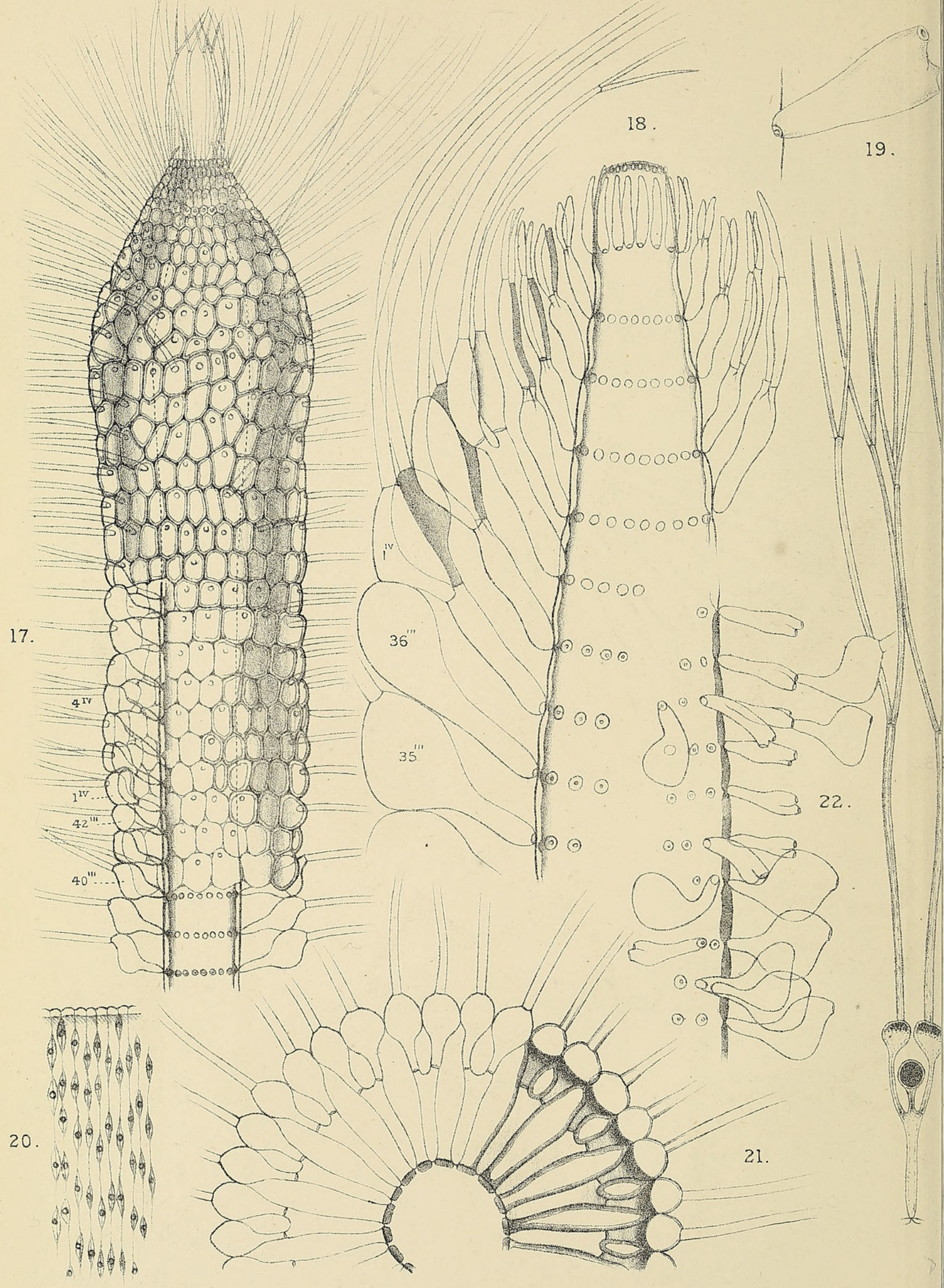

A.H. Church del. 


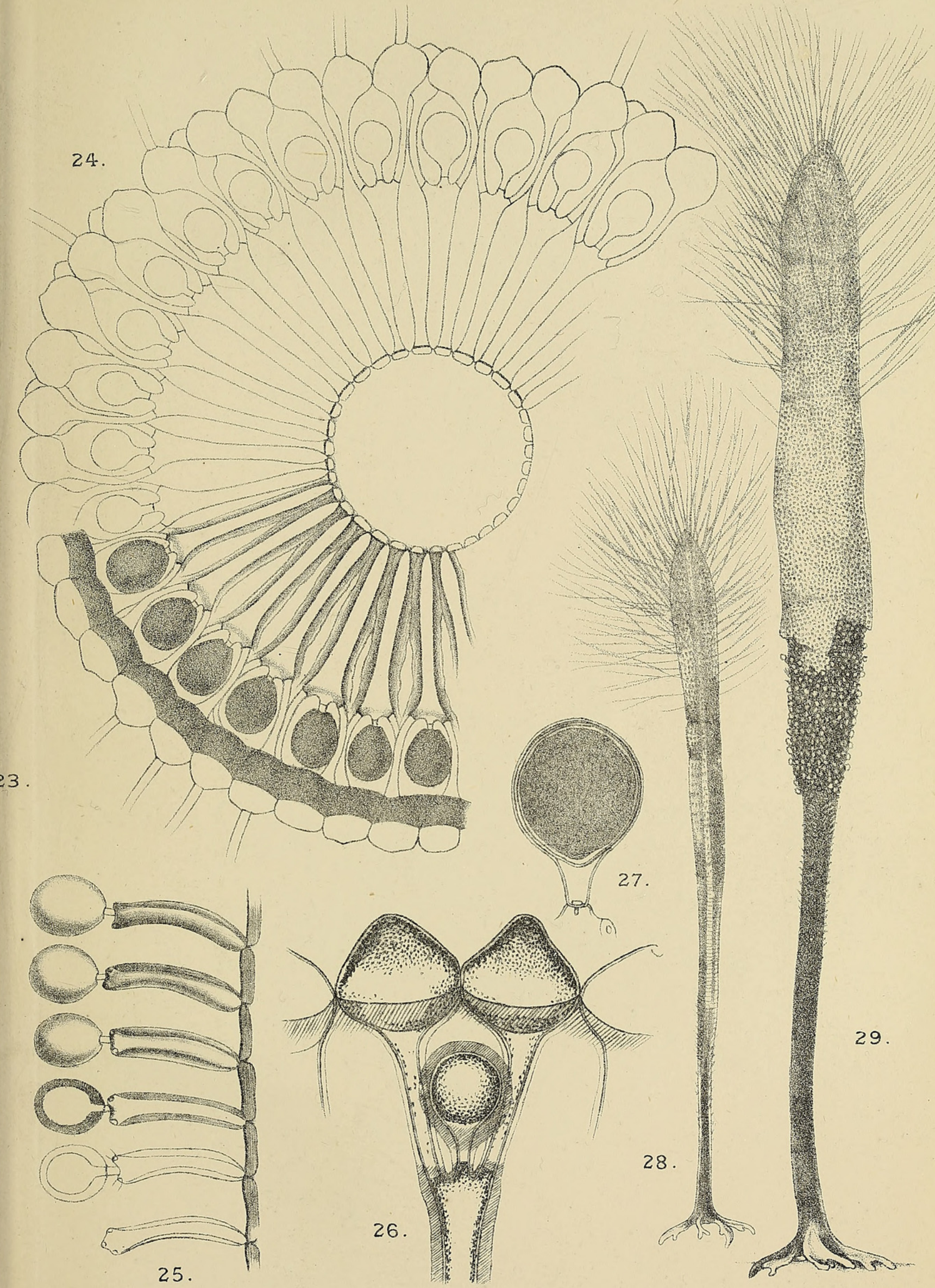

University Press, 0xford. 

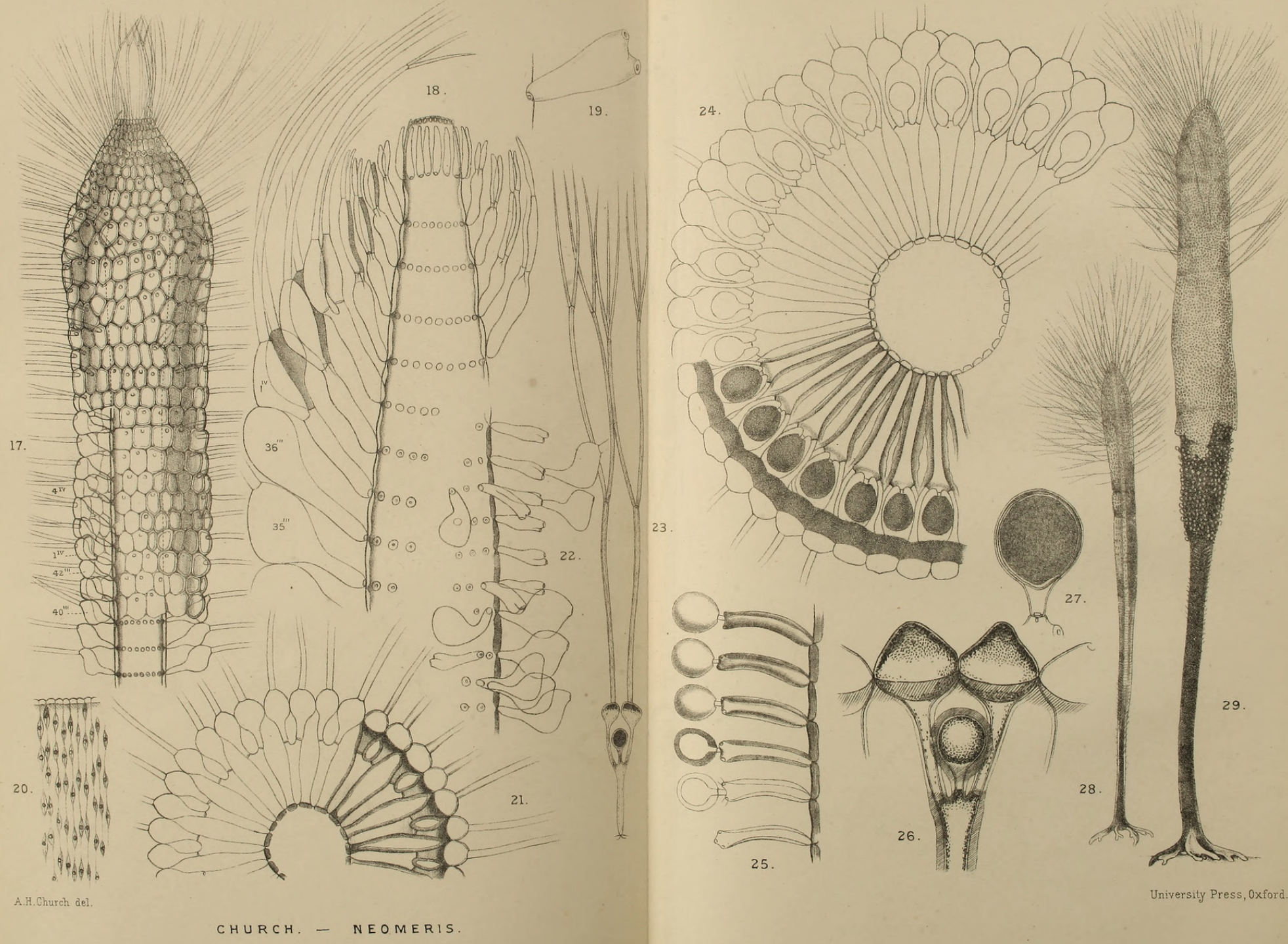

University Press, 0xford. 
i

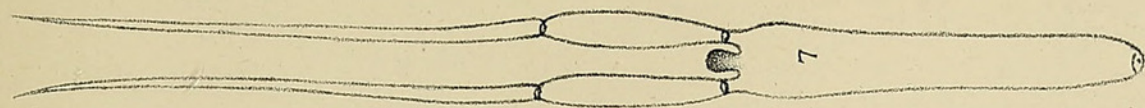

$\exists$

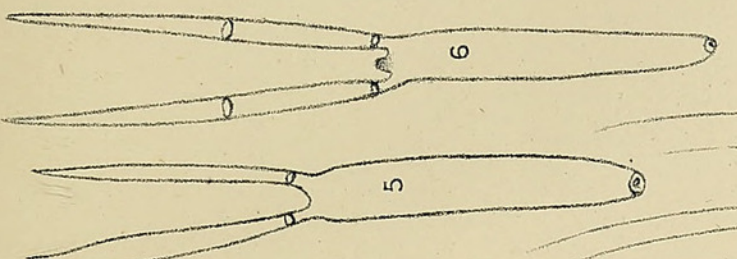

$m$

के +

$\overbrace{m}^{3}$

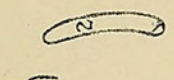
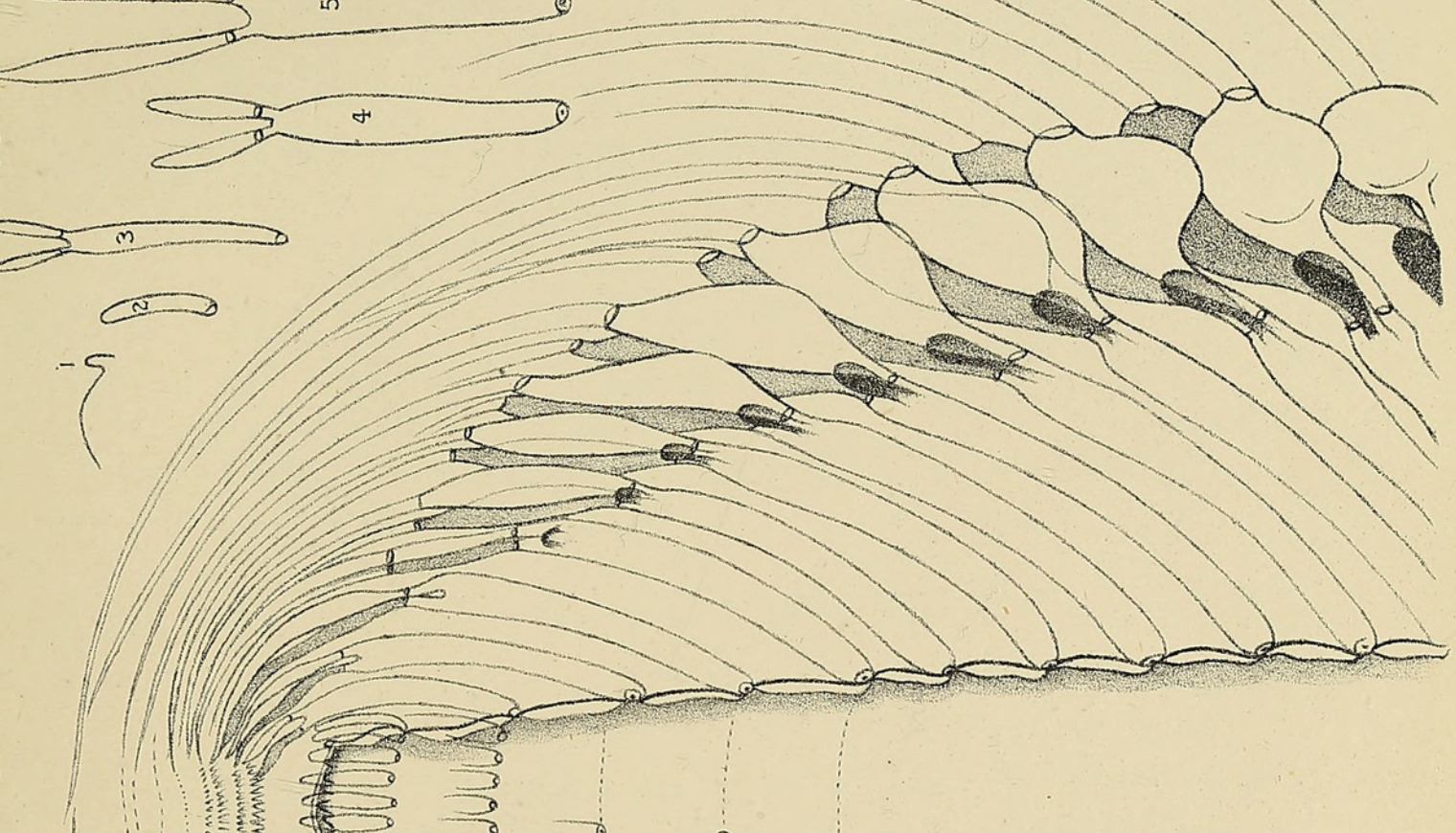

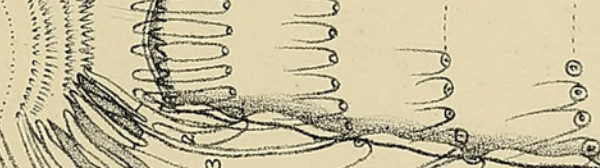

$1 M M L^{2}$

$1 / \frac{\pi}{\frac{\pi}{2} \text { in }}$

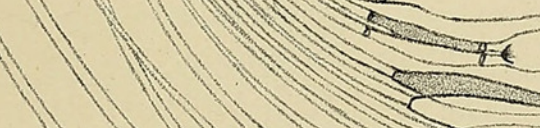

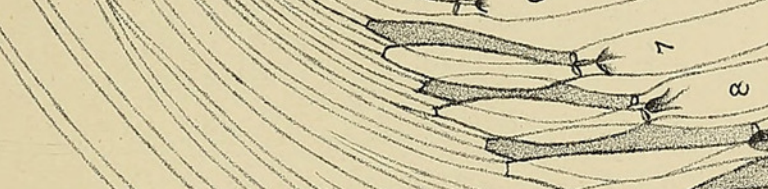
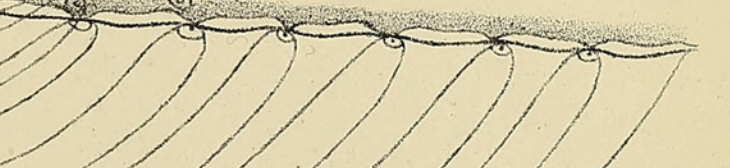

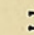

$u$

כ

I

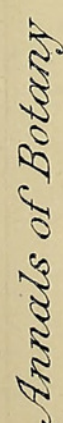
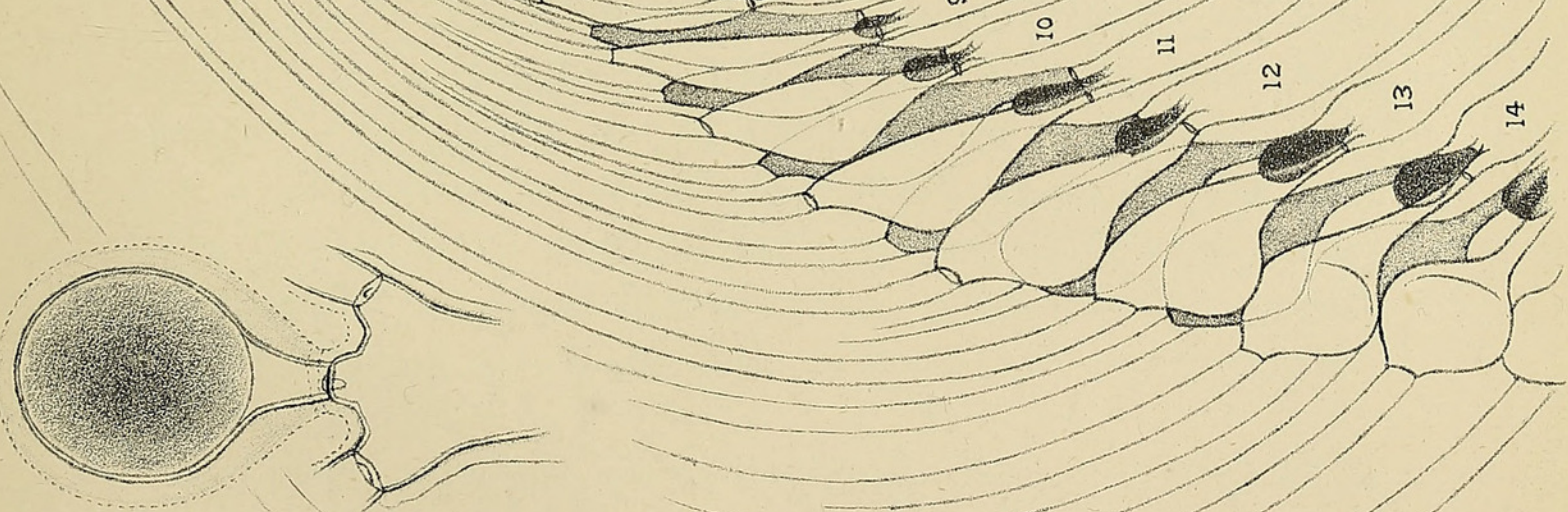

$\vec{m}$

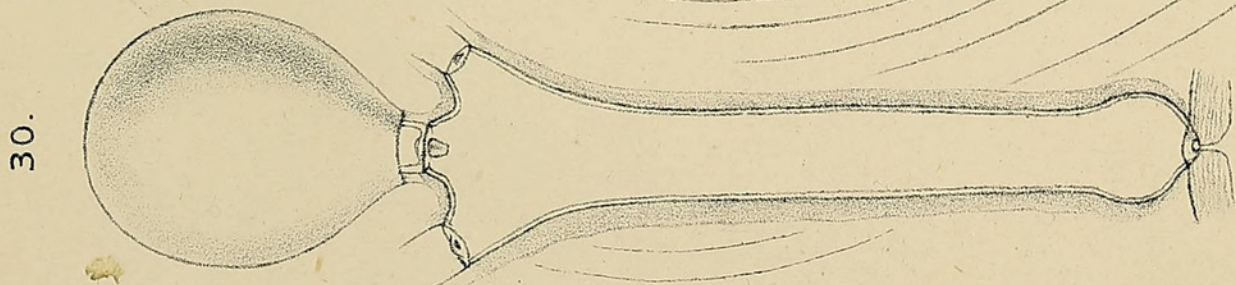




\section{$2 \mathrm{BHL}$ Biodiversity Heritage Library}

Church, A. H. 1895. "The structure of the thallus of Neomeris dumetosa, Lamour." Annals of botany 9, 581-608.

https://doi.org/10.1093/oxfordjournals.aob.a090757.

View This Item Online: https://www.biodiversitylibrary.org/item/233478

DOI: https://doi.org/10.1093/oxfordjournals.aob.a090757

Permalink: https://www.biodiversitylibrary.org/partpdf/318396

\section{Holding Institution}

Smithsonian Libraries

\section{Sponsored by}

Biodiversity Heritage Library

\section{Copyright \& Reuse}

Copyright Status: Not in copyright. The BHL knows of no copyright restrictions on this item.

This document was created from content at the Biodiversity Heritage Library, the world's largest open access digital library for biodiversity literature and archives. Visit BHL at https://www.biodiversitylibrary.org. 